\title{
Establishment of normal reference ranges for total and separate glomerular filtration rates in living kidney donors by Gates' method after renal depth measured using single-photon emission computed tomography/computed tomography
}

\author{
Yushan Wei ${ }^{1,2}$, Yan Liu ${ }^{1}$, Qiang Li $^{3}$, Yuemin Zhang ${ }^{1}$, Qi Wang ${ }^{1}$, Yiyuan Yang ${ }^{1}$, Yiqian Liang ${ }^{1}$, Aomei Zhao ${ }^{1}$, \\ Aimin Yang ${ }^{1}$, Jianjun Xue ${ }^{1}$ \\ ${ }^{1}$ Department of Nuclear Medicine, First Affiliated Hospital of Xi'an Jiaotong University, Xi'an, China; ${ }^{2}$ Department of Medical Imaging, Xi'an Chest \\ Hospital, Xi'an, China; ${ }^{3}$ Department of Health Statistics, School of Medicine Xi'an Jiaotong University, Xi'an, China
}

Correspondence to: Dr. Jianjun Xue. Department of Nuclear Medicine, First Affiliated Hospital of Xi'an Jiaotong University, Xi'an, China.

Email: xuejianjun@mail.xjtu.edu.cn.

Background: The underestimation of renal depth by Tønnesen formula in Gates' method, which has been confirmed by many scholars, leads to the underestimation of both separate glomerular filtration rate (gSGFR) and total glomerular filtration rate (gTGFR). This study aimed to establish the normal reference ranges of renal depth-calibrated gTGFR and gSGFR in Chinese healthy adults, and to analyze the influencing factors. Methods: Renal depth was measured by CT scan followed by technetium $99 \mathrm{~m}$-diethylene triamine pentaacetic acid ( $\left.{ }^{99 \mathrm{~m}} \mathrm{Tc}-\mathrm{DTPA}\right)$ renal dynamic imaging by single-photon emission computed tomography/ computed tomography (SPECT/CT) in 329 living kidney donors. The renal depth-calibrated gTGFR and gSGFR were calculated by Gates' method with renal depth measured by CT instead of being calculated by the Tønnesen formula. A general linear model based on age, gender, body height, body weight, and BMI was used to analyze factors influencing gSGFR (L), gSGFR (R) and gTGFR.

Results: The average gSGFR (L), gSGFR (R), and gTGFR for patients aged 23-64 years old were $49.3 \pm 10.1,49.9 \pm 10.4$, and $99.1 \pm 18.7 \mathrm{~mL} / \mathrm{min} / 1.73 \mathrm{~m}^{2}$, respectively. The gSGFR (L), gSGFR (R) and gTGFR for patients aged 41-50 years old were $26.9-69.3,27.7-68.8$, and $57.5-135.3 \mathrm{~mL} / \mathrm{min} /$ $1.73 \mathrm{~m}^{2}$, respectively, and those for patients aged 51-60 years old were 31.0-61.5, 29.5-63.3, and 64.6$120.7 \mathrm{~mL} / \mathrm{min} / 1.73 \mathrm{~m}^{2}$, respectively. gSGFR (L), gSGFR (R) and gTGFR had statistical significance with body height and age $(\mathrm{P}<0.05)$; however, there was no significant difference with gender, body weight, and BMI $(\mathrm{P}>0.05)$. For each 1 year increase in age, the gSGFR (L), gSGFR (R), and gTGFR decreased by 0.17 , 0.28 , and $0.44 \mathrm{~mL} / \mathrm{min} / 1.73 \mathrm{~m}^{2}$, respectively, while for every $1 \mathrm{~cm}$ increase in body height, the gSGFR (L), gSGFR (R), and gTGFR decreased by $0.37,0.36$, and $0.74 \mathrm{~mL} / \mathrm{min} / 1.73 \mathrm{~m}^{2}$, respectively.

Conclusions: Normal reference ranges for renal depth-calibrated gSGFR (L), gSGFR (R), and gTGFR were established in healthy Chinese adults aged 23-64 years, and gSGFR (L), gSGFR (R), and gTGFR decreased with age and body height.

Keywords: Glomerular filtration rate (GFR); ${ }^{99 m}$ Tc-DTPA; normal reference range; donor; kidney depth; SPECT/CT

Submitted Sep 16, 2019. Accepted for publication Jun 22, 2020.

doi: 10.21037/qims-19-772

View this article at: http://dx.doi.org/10.21037/qims-19-772 


\section{Introduction}

Glomerular filtration rate (GFR), the volume of glomerular filtrate formed per minute in the nephrons of the kidneys, is the best indicator for evaluating renal function $(1,2)$. GFR can be obtained by measuring the filtration rate of the endogenous markers serum creatinine (Scr), blood urea nitrogen (BUN), and Cystatin $\mathrm{C}$, as well as exogenous markers including inulin and radioisotopes.

The most widely used marker for assessing renal function and for estimating GFR is the measurement of Scr and creatinine clearance rate (Ccr). Scr is primarily a metabolite of creatine phosphate, and a small amount $(15 \%)$ can be secreted through the renal tubules. Studies have shown that Scr concentration can be affected by age, body height, body weight, sex, race, muscle mass, and various medications; therefore, Scr is now recognized as being unreliable for predicting renal function $(3,4)$.

BUN is the final degradation product of protein and amino acid metabolism, and $40-50 \%$ can be reabsorbed by renal tubules. It is affected by protein intake, decomposition level, and renal blood flow, as well as some drugs. A number of studies have reported $(5,6)$ that Scr and BUN can maintain a normal level, even when the GFR decreases by $50 \%$; therefore, Scr and BUN clearance are not accurate enough for measuring GFR.

Cystatin C, which is filtered through the glomeruli, and not secreted or reabsorbed by the renal tubules or bound with plasma proteins, is considered to be an ideal marker for measuring GFR. It also has higher sensitivity and specificity than Scr and BUN. Unfortunately, Cystatin C clearance has not been popularized as a means of measuring GFR in clinics in China.

Inulin, which is completely filtered by the glomeruli, is not metabolized or destroyed in the body, secreted or reabsorbed by renal tubules, or bound with plasma proteins. It is an ideal exogenous marker that reflects changes of GFR. Therefore, inulin clearance is recognized as the gold standard for the measurement of GFR $(7,8)$. However, the measurement of inulin clearance requires both blood and urine to be accurately collected multiple times. It is a complex, cumbersome, and time-consuming process, which makes it difficult to carry out in clinical practice.

Measuring the clearance of radionuclide markers can be done through plasma clearance rate and renal dynamic imaging. To measure the plasma clearance of radioactive markers, blood samples are collected from multiple time phases and plasma radioactivity counts are measured. GFR is then obtained through a multi-compartment model (9). It can be divided into single-phase, double-phase, and threephase plasma methods. The single-phase method has poor accuracy, while the two-phase and three-phase methods have good correlation and are considered to be accurate in the determination of GFR. Therefore, these were chosen as the reference methods in the current study $(10,11)$. However, they are time consuming to perform and are not currently applied in clinical practice (11). Radionuclide markers mainly include chromium 51-ethylenediamine tetraacetic acid $\left({ }^{51} \mathrm{Cr}\right.$-EDTA $)$, technetium ${ }^{99 \mathrm{~m}}$-diethylene triamine pentaacetic acid $\left.{ }^{99 \mathrm{~m}} \mathrm{Tc}-\mathrm{DTPA}\right)$, and ${ }^{125} \mathrm{I}$-Iolamate. GFR measured by ${ }^{51} \mathrm{Cr}$-EDTA plasma clearance is considered to be an acceptable substitute for the gold standard, inulin clearance (8). After filtration by the glomeruli without tubular absorption, only $5 \%$ of ${ }^{99 \mathrm{~m}} \mathrm{Tc}-\mathrm{DTPA}$ is combined with plasma protein. When the GFR $>30 \mathrm{~mL} / \mathrm{min} / 1.73 \mathrm{~m}^{2}$, the clearance of ${ }^{99 \mathrm{~m}} \mathrm{Tc}-\mathrm{DTPA}$ and ${ }^{51} \mathrm{Cr}$-EDTA is reliable and shows good correlation (12). Garcia-Covarrubias et al. also reported that the GFR measured by Gates' method in renal allograft donors was strongly correlated with that estimated by Cystatin C clearance (13). In 1996, ${ }^{99 m}$ Tc-DTPA double plasma sample method was recommended by the American Nuclear Medical Association as the gold standard for the clinical determination of GFR (6).

The methods above can measure the total glomerular filtration rate (TGFR) but cannot measure the separate glomerular filtration rate (SGFR). The gamma camera uptake method (also called Gates' method) (14), with ${ }^{99 \mathrm{~m}} \mathrm{Tc}-$ DTPA is a simple, convenient and effective way to calculate SGFR. The formula for Gates' method is shown in Supplement $1(11,15)$. While the Itoh and Arakawa method can be used to determine SGFR (see Supplement 1) (16), in clinical practice, the Gates' method has been adopted most widely and is possibly the simplest method. With no need to draw blood and urine, and with good repeatability and high accuracy, it is recommended as a routine method for clinical evaluation of total and separate renal function (17). Kidney depth is the most important factor affecting the glomerular filtration rate measured by Gates' method (gGFR) (14), and estimated by using the Tønnesen formula (see Supplement 1), which was derived from B-mode ultrasound findings of 55 patients in the sitting position in 1974. A large number of studies have reported that kidney depth is underestimated by the Tønnesen formula (18-21), and the main correction method is to measure renal depth using CT. Our study showed that the total glomerular filtration rate measured by Gates' method (gTGFR) and the separate glomerular 
Table 1 General data of 329 donors and gSGFR (L), gSGFR (R) and gTGFR values $(\bar{x} \pm s)$

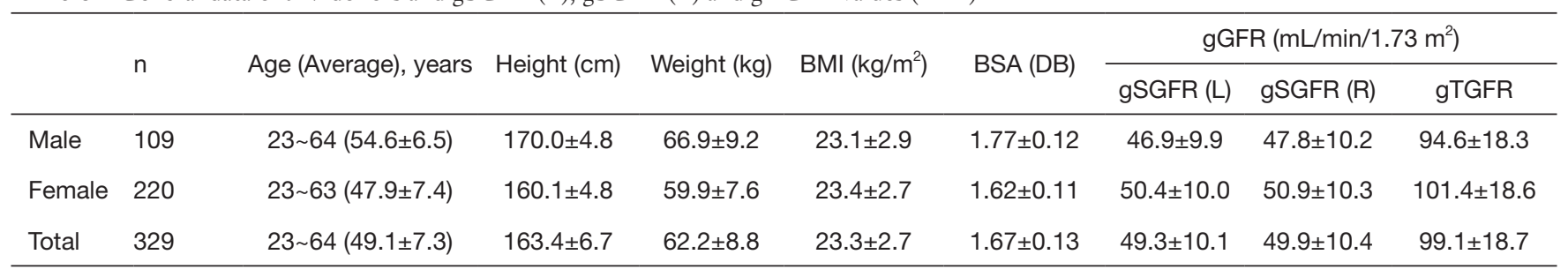

gSGFR, separate glomerular filtration rate measured by Gates' method; gTGFR, total glomerular filtration rate measured by Gates' method.

filtration rate measured by Gates' method (gSGFR) were also underestimated by the Tønnesen formula (22). To protect the safety of donors and recipients, the Chinese clinical guidelines for living donor renal transplantation (2016 edition) recommend that Gates' method should be used to measure GFR, and gSGFR should be no less than $40 \mathrm{~mL} / \mathrm{min} / 1.73 \mathrm{~m}^{2}(23)$. However, there are few reports on the normal reference range for gSGFR in China, and the normal reference ranges for gTGFR and gSGFR after kidney depth has been measured by CT in Gates' method have not been reported.

Kidney depth can also be measured by radionuclide lateral imaging, however, renal depth measured by CT has been reported to be more accurate than by ultrasound (24), or radionuclide lateral imaging (25). Moreover, accurate measurement of renal depth in Gates' method can improve the accuracy of gTGFR and gSGFR.

To establish accurate reference ranges for renal depthcalibrated gTGFR and gSGFR in this study, the kidney depth of healthy living potential kidney donors was measured by CT. CT-measured renal depth, instead of the Tønnesen formula, were used to calculate the GFR by Gates' method. Normal reference ranges for renal depthcalibrated gTGFR and gSGFR were then established, and the influencing factors were analyzed.

\section{Methods}

\section{Patients}

Between October, 2010 and January, 2019, 329 healthy living kidney donors were enrolled in this study. The gender, age, body height, body weight, and body mass index (BMI) [weight $(\mathrm{kg}) /$ height $(\mathrm{m})^{2}$ ] of the donors were recorded (Table 1). Renal depth was measured by CT during single-photon emission computed tomography/ computed tomography (SPECT/CT) renal dynamic imaging, and the GFR was calculated by Gates' method. All of the donors were healthy, and had no history of kidney disease, hypertension, diabetes mellitus, or injury. Before examination, a series of routine measurements such as blood pressure, electrocardiogram, routine bloods, routine urine, blood sugar, liver function, kidney function, liver and kidney ultrasound, and donor-recipient human leukocyte antigen matching were performed. Results were normal and met donor-recipient matching conditions. Ultrasound confirmed that the position of the kidneys was normal. Renal dynamic imaging was carried out in accordance with the operation manual and all interfering factors was considered. This study was reviewed and approved by the Ethics Committee of the First Affiliated Hospital of Xi'an Jiaotong University (Xi'an, China), and all patients signed a written informed consent before participating in the study.

\section{Instruments and methods}

\section{Kidney dynamic imaging}

The radiochemical purity of ${ }^{99 \mathrm{~m}} \mathrm{Tc}-\mathrm{DTPA}$ was more than $95 \%$. Each patient's age and gender were recorded, and their height and body weight were measured. Thirty minutes before imaging, the patients drank 300-500 Ml of water and then emptied their bladders. The procedure began with the patients, who were in the supine position, being injected with $185 \mathrm{MBq}$ of ${ }^{99 \mathrm{~m}} \mathrm{Tc}-\mathrm{DTPA} .{ }^{99 \mathrm{~m}} \mathrm{Tc}-\mathrm{DTPA}$ renal dynamic imaging was acquired for 20 minutes using a GE Infinia VC Hawkeye-4 SPECT/CT scanner (GE Healthcare, America) equipped with a low-energy highresolution collimator, a peak energy of $140 \mathrm{keV}$, a $64 \times 64$ matrix, and a window width of $20 \%$. The total injected counts were determined by subtracting the post-injection counts from the pre-injection counts.

\section{Renal depth measured by CT}

The distance from the kidney anterior surface to the skin 
and from the kidney posterior surface to the skin at the level of the renal hilum was measured using a GE Infinia VC Hawkeye-4 SPECT/CT scanner (GE Healthcare, America), respectively; the average of these two values was the mean renal depth (Figure 1) (18).

\section{Measurement of gGFR}

The region of interest was manually defined around the frame of each kidney, and a semi-lunar background region was automatically placed around the lower, outer renal margin. After the kidney depth measured by CT was entered into computer, the SPECT processing software automatically calculated the un-calibrated gGFR according

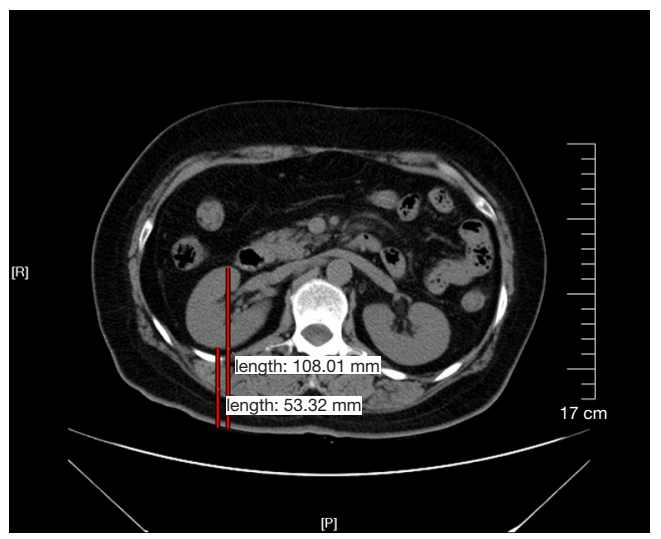

Figure 1 The image shows the distance from the skin of the back to the anterior or posterior surfaces of each kidney at the level of the renal hilum; the average of these two values was calculated to obtain the renal depth of each kidney. to the Gates' algorithm. Body surface area (BSA) was calculated using the Du Bois and Du Bois BSA equation, BSA normalized GFR $\mathrm{mL} / \mathrm{min} / 1.73 \mathrm{~m}^{2}$ ) = Absolute GFR $(\mathrm{mL} / \mathrm{min}) \times\left(1.73 \mathrm{~m}^{2} /\right.$ Patients BSA $)$.

\section{Statistical analysis}

Data were analyzed using SPSS version 18.0 (SPSS Inc., Chicago, IL, USA) statistical software. The measurement data were expressed as mean \pm standard deviation (SD). A general linear model was used; the independent variables included age, gender, body height, body weight, and BMI, and the dependent variables were gSGFR (L), gSGFR (R), and gTGFR. The mean scores for gSGFR (L) and gSGFR (R) in each group were compared by paired $t$-test. $\mathrm{P}<0.05$ was considered to show statistical significance. Normal reference ranges were mean $\pm 1.96 \mathrm{SD}$ (26).

\section{Results}

The data of the 329 patients in this study, including age, body height, body weight, BMI, BSA, gSGFR (L), gSGFR (R), and gTGFR are shown in Table 1. The average values of gSGFR (L), gSGFR (R), and gTGFR in the 329 donors were $49.3 \pm 10.1,49.9 \pm 10.4$, and $99.1 \pm 18.7 \mathrm{~mL} / \mathrm{min} / 1.73 \mathrm{~m}^{2}$, respectively. The distribution of gTGFR according to age in male and female patients is shown in Figure 2.

The normal reference ranges for gSGFR (L), gSGFR (R), and gTGFR in 152 donors aged 41-50 years and 135 donors aged 51-60 years are shown in Table 2. There were 28 and 14 patients aged $<40$ years old and $>60$ years

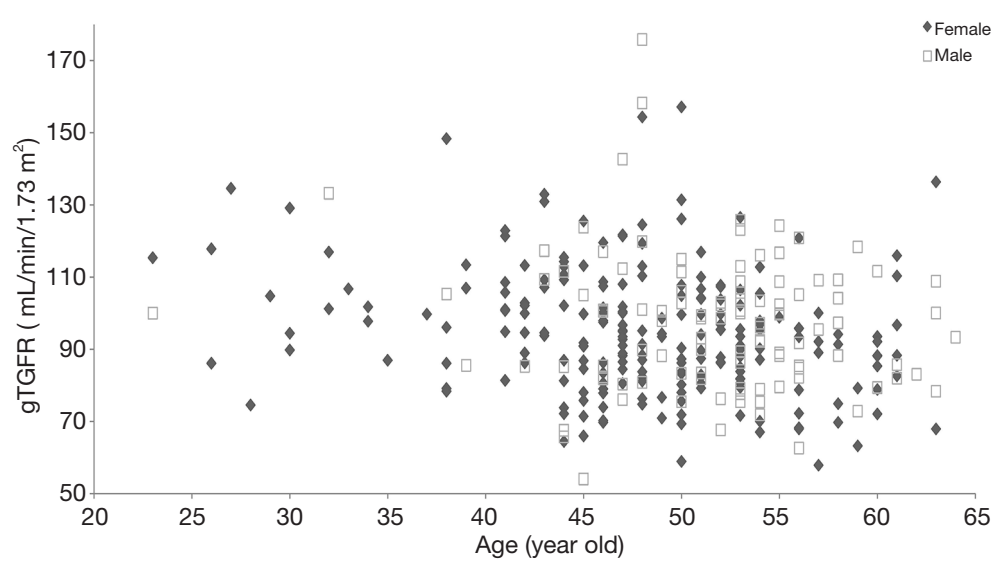

Figure 2 The scatter plot of gTGFR distribution with age in male and female patients. gTGFR, total glomerular filtration rate measured by Gates' method. 
Table 2 The normal reference ranges of gSGFR (L), gSGFR (R), gSGFR and gTGFR in 152 donors aged $41-50$ years and 135 donors aged 51-60 years (bilateral, $\bar{x} \pm 1.96 s$ )

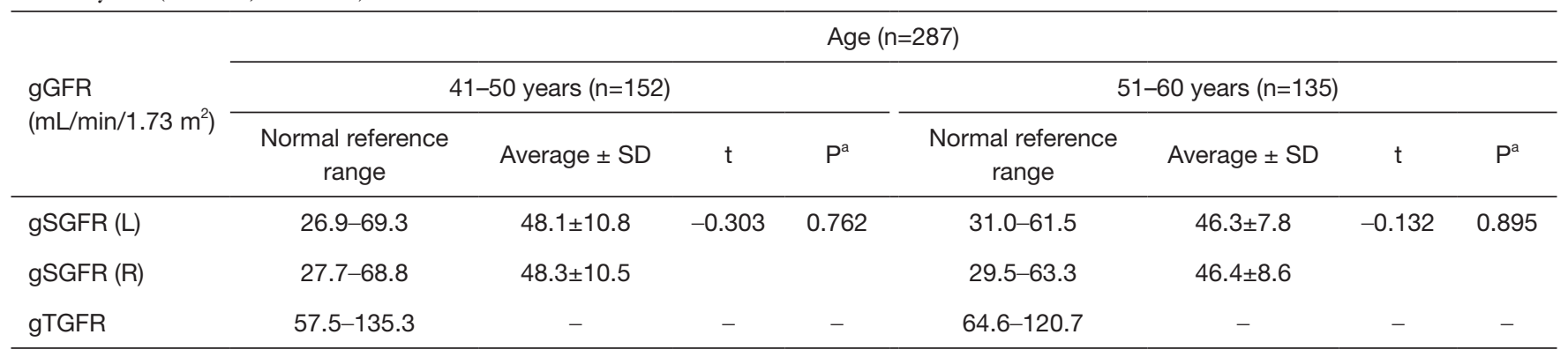

a , P values were estimated using paired t test for comparing gSGFR of left and right kidney. gSGFR, separate glomerular filtration rate measured by Gates' method; gTGFR, total glomerular filtration rate measured by Gates' method.

Table 3 General linear model analysis of gSGFR (L) in 329 living donors

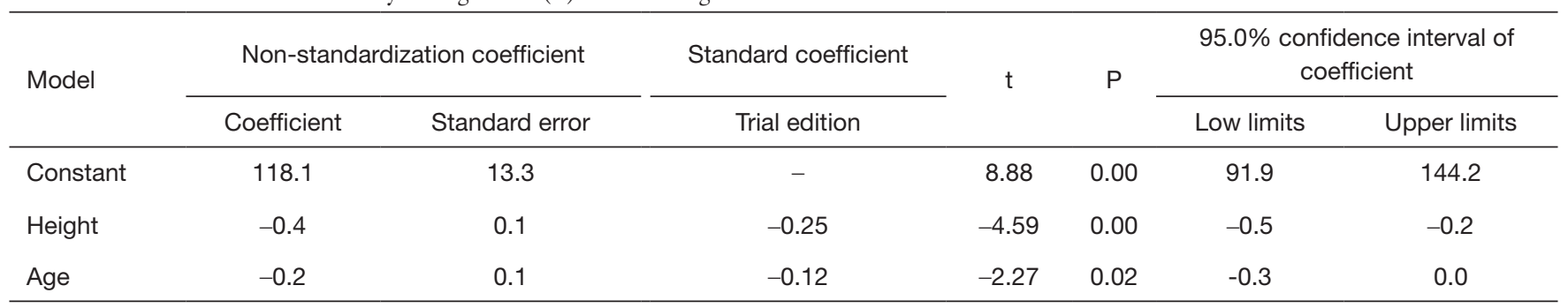

Dependent Variable: gSGFR (L). gSGFR, separate glomerular filtration rate measured by Gates' method.

Table 4 General linear model analysis of gSGFR (R) in 329 living donors

\begin{tabular}{|c|c|c|c|c|c|c|c|}
\hline \multirow[t]{2}{*}{ Model } & \multicolumn{2}{|c|}{ Non-standardization coefficient } & \multirow{2}{*}{$\frac{\text { Standard coefficient }}{\text { Trial edition }}$} & \multirow[t]{2}{*}{$\mathrm{t}$} & \multirow[t]{2}{*}{$\mathrm{P}$} & \multicolumn{2}{|c|}{$\begin{array}{c}95.0 \% \text { confidence interval of } \\
\text { coefficient }\end{array}$} \\
\hline & Coefficient & Standard error & & & & Low limits & Upper limits \\
\hline Constant & 121.8 & 13.5 & - & 9.04 & 0.00 & 95.3 & 148.4 \\
\hline Height & -0.4 & 0.1 & -0.2 & -4.37 & 0.00 & -0.5 & -0.2 \\
\hline
\end{tabular}

Dependent Variable: gSGFR(R). gSGFR, separate glomerular filtration rate measured by Gates' method.

old, respectively; because of these limited sample sizes, and with fewer values for reference, the normal ranges of these two groups of patients are not reported in Table 2. The average value of $\mathrm{gSGFR}(\mathrm{L})$ and $\mathrm{gSGFR}(\mathrm{R})$ in the $41-50$ years age group was $48.1 \pm 10.8$ and $48.3 \pm$ $10.5 \mathrm{~mL} / \mathrm{min} / 1.73 \mathrm{~m}^{2}$, respectively. The average value of gSGFR (L) and gSGFR (R) in the 51-60 age group was $46.3 \pm 7.8$ and $46.4 \pm 8.6 \mathrm{~mL} / \mathrm{min} / 1.73 \mathrm{~m}^{2}$, respectively. There were no significant differences in gSGFR between the left and right kidney in these two age groups $(\mathrm{P}=0.785$ and 0.887 , respectively).
The results of the general linear model analysis in the 329 living donors (see Tables 3-5) showed there to be significant differences in gSGFR (L), gSGFR (R), and gTGFR according to age and body height $(\mathrm{P}<0.05)$. However, there were no significant differences according to gender, body weight, or BMI $(\mathrm{P}>0.05)$. For every 1 -year increase in age, gSGFR (L), gSGFR (R), and gTGFR decreased by $0.17,0.28$, and $0.44 \mathrm{~mL} / \mathrm{min} / 1.73 \mathrm{~m}^{2}$, respectively; and for every $1-\mathrm{cm}$ increase in height, gSGFR (L), gSGFR (R), and gTGFR decreased by $0.37,0.36$, and $0.74 \mathrm{~mL} / \mathrm{min} / 1.73 \mathrm{~m}^{2}$, respectively. 
Table 5 General linear model analysis of gSGFR (T) in 329 living donors

\begin{tabular}{|c|c|c|c|c|c|c|c|}
\hline \multirow[t]{2}{*}{ Model } & \multicolumn{2}{|c|}{ Non-standardization coefficient } & \multirow{2}{*}{$\frac{\text { Standard coefficient }}{\text { Trial edition }}$} & \multirow[t]{2}{*}{$\mathrm{t}$} & \multirow{2}{*}{$\mathrm{P}$} & \multicolumn{2}{|c|}{$\begin{array}{c}95.0 \% \text { confidence interval of } \\
\text { coefficient }\end{array}$} \\
\hline & Coefficient & Standard error & & & & Low limits & Upper limits \\
\hline Height & -0.7 & 0.2 & -0.3 & -4.98 & 0.00 & -1.0 & -0.4 \\
\hline
\end{tabular}

Dependent Variable: gTGFR. gTGFR, total glomerular filtration rate measured by Gates' method.

\section{Discussion}

Currently, Gates' method is the most widely used method for measuring SGFR, and it has important clinical significance in the evaluation of the single renal function of living donors. Gates' method has some major benefits; these include its noninvasive nature and its incorporation of total and split GFRs of the kidneys. However, this method also has some disadvantages in terms of the quantifying of the GFR of kidney, and the measurements may be affected by some interfering factors. These include: the patient needing to be well hydrated before radiopharmaceutical administration; the quality of the 'bolus-like' injection, the position of the kidney, positioning of the patient during imaging acquisition, furosemide administration, kidney depth, total thickness of the body at the level of the kidney, and the region of interest. However, most of these factors can be controlled by following standardized acquisition and processing procedures. Hydronephrosis caused by ureteral obstruction also affects GFR (27). In this study the position of the kidneys was normal, as confirmed by ultrasound, and furosemide was not used during the examination. In some studies, total thickness of the body at the level of the kidneys has been mentioned as an important variable $(28,29)$. Several concerns in relation to total thickness in GFR formulas were discussed in our previous study (19). It is a generally fact that total thickness cannot be easily measured in the clinical setting because there is no clear mark for the renal hilum on the surface of the body. However, both the total thickness of the body at the level of the kidney and kidney depth can be measured by CT (19).

Kidney depth is the most important factor affecting the measurement of gGFR in Gates' method (14). There are several methods by which renal depth can be measured, including ultrasound, CT, and ${ }^{99 \mathrm{~m}}$ Tc-DTPA scintigraphy. In Gates' method the renal depth is estimated by a formula. Many studies have confirmed that renal depth is more accurate when measured by CT than by ultrasound in Gates' method. Lateral ${ }^{99 \mathrm{~m}}$ Tc-DTPA scintigraphy is used to measure renal depth and carries the advantage of not exposing the patient to unnecessary radiation. Sugawara et al. reported that the depth of both kidneys as measured by ${ }^{99 \mathrm{~m}}$ Tc-DTPA renography was equivalent to that measured by CT (30); however, further studies are required to verify this. According to the attenuation coefficient of ${ }^{99 \mathrm{~m}} \mathrm{Tc}$ in human soft tissue as 0.153 , a $+/-$ $1 \mathrm{~cm}$ error in the estimation of renal depth will lead to a $14-16 \%$ overestimated/underestimated in calculated GFR $(31,32)$. Since the underestimation of renal depth by Tønnesen formula in Gates' method $(18,19,21)$ leads to the underestimation of TGFR and gSGFR (22), the correction of renal depth will improve the accuracy of gGFR measurement. To our knowledge, there is no data on the measurement of gGFR after renal depth has been corrected. At present the guidelines for living donor kidney transplantation in Europe and America state that the required GFR of donors is $>90 \mathrm{~mL} / \mathrm{min} / 1.73 \mathrm{~m}^{2}$, without mentioning SGFR. In clinic, however, impaired renal function on one side is not uncommon even when the gTGFR of donors is normal. Clinical Guidelines on Living Donor Renal Transplantation in China (2016 Edition) recommend that SGFR should be measured by radioisotope scanning, and the gSGFR be no less than $40 \mathrm{~mL} / \mathrm{min} /$ $1.73 \mathrm{~m}^{2}(23)$. However, in China, the unit of gGFR value is mostly in $\mathrm{mL} / \mathrm{min}$, not $\mathrm{mL} / \mathrm{min}$ per $1.73 \mathrm{~m}^{2}$, leading to difficulties in the comparison of gGFR between patients, and for now, the normal reference range for normalized gSGFR has yet to be reported. This study showed that the mean values of gSGFR (L), gSGFR (R) and gTGFR after renal depth was measured by CT were $49.3 \pm 10.1$, $49.9 \pm 10.4$, and $99.1 \pm 18.7 \mathrm{~mL} / \mathrm{min} / 1.73 \mathrm{~m}^{2}$, respectively. To better protect the safety of living kidney transplantation donors and recipients, the normal reference ranges for gSGFR (L), gSGFR (R), and gTGFR in Chinese adults 
aged 23-64 years have been determined in this study. Most researchers currently believe that GFR decreases with age. Grewal et al. (33) reported that the plasma-based glomerular filtration rate (pGFR) of ${ }^{51} \mathrm{Cr}$-EDTA decreased by $9.1 \mathrm{~mL} / \mathrm{min} / 1.73 \mathrm{~m}^{2}$ every 10 years after the age of 40 years old, and a meta-analysis by Granerus et al. (34) including 8 reports of inulin clearance and ${ }^{51} \mathrm{Cr}$-EDTA pGFR clearance showed that GFR declined slowly up to 50 years old, with a decrease of about $4 \mathrm{~mL} / \mathrm{min}$ per decade, before its decrease accelerated after the age of 50 to about $10 \mathrm{~mL} / \mathrm{min}$ per decade. In contrast, some researchers have concluded that there is no significant relationship between age and GFR. In 2008, Piepsz et al. suggested for the first time that the normal GFR value in children was $107 \mathrm{~mL} / \mathrm{min} /$ $1.73 \mathrm{~m}^{2}$ (35,36); and a later meta-analysis by Pottel et al. (26) mentioned that there was no difference between the average GFR of adults aged 20-30 years and that of children, while the GFR value of 30-40 year old adults was $104.9 \mathrm{~mL} / \mathrm{min} /$ $1.73 \mathrm{~m}^{2}$. This was slightly different from $107 \mathrm{~mL} / \mathrm{min} /$ $1.73 \mathrm{~m}^{2}$, but from a clinical point of view, the difference was not significant. The results of this study are consistent with the belief that GFR decreases with age, showing that the gSGFR (L), gSGFR (R), and gTGFR were all decreased in older patients. This study further provides the normal reference ranges for gSGFR (L), gSGFR (R), and gTGFR for donors at different ages; for normal adults aged 2364 years, a 1-year increase in age will lead to a $0.17,0.28$, and $0.44 \mathrm{~mL} / \mathrm{min} / 1.73 \mathrm{~m}^{2}$ decrease in gSGFR (L), gSGFR (R), and gTGFR, respectively. Moreover, no significant differences were observed in gSGFR between the left and right kidneys in the 41-50 age group nor in the 51-60 age group. Hence, the normal reference range of one side could be used for both kidneys.

It has been reported that GFR may be related to gender (37), and that the decline of GFR tends to be slower and delayed with the increase of women's age compared to men. (38). Granerus et al. (34) demonstrated that male BSA is larger than female BSA, which leads to higher GFR in males than in females. Berg (1) reported for the first time that the GFR of men began to decrease after the age of 20 by an average of $8.7 \mathrm{~mL} / \mathrm{min} / 1.73 \mathrm{~m}^{2}$ every 10 years, while that of women did not decrease between the ages of 20 and 50 years. Berg demonstrated that this might be related to the protection of premenopausal estrogen in women (1). Baylis and Corman found that female rats were free of agedependent GFR decline compared with male rats (39), as well as that the protection of estrogen on renal function disappeared in postmenopausal women but could be restored by estrogen substitutes (39). However, some scholars have put forward opposing views; Granerus et al. (34), for instance, stated that GFR was not related to gender after studying ${ }^{51} \mathrm{Cr}$-EDTA pGFR values in 428 potential kidney donors aged 19-72 years. Pottel et al. (26) conducted a meta-analysis including 2,565 male and 2,917 female healthy living potential kidney donors, and the results showed that there was no significant difference in GFR between men and women in different age groups (40). This study supported the latter results, finding that gSGFR (L), gSGFR (R), and gTGFR were not related to gender, body weight, or BMI, but were related to body height.

In order to compare the gGFR of different patients, it is necessary to standardize the gGFR value; at present, BSA is the most commonly used standardized parameter. It is generally accepted that if GFR has been normalized to BSA, the correlation to body height and body weight is not exist, and the impact of BSA normalized GFR values is scarce in an average size population with a standard BSA of around $1.73 \mathrm{~m}^{2}$ (41). But this study shows that for each 1-cm increase in body height, normalized gSGFR (L), gSGFR (R), and TGFR decrease by $0.37,0.36$, and $0.74 \mathrm{~mL} / \mathrm{min} /$ $1.73 \mathrm{~m}^{2}$, respectively. The reason for this may be related to the selection of average BSA $\left(1.73 \mathrm{~m}^{2}\right)$ and BSA standardized formula. BSA normalized GFR = Absolute GFR * $\left(1.73 \mathrm{~m}^{2} /\right.$ Patients BSA); $1.73 \mathrm{~m}^{2}$ obtained by Mcintosh et al. in 1928 with the data of 8 children and 7 healthy adults $(42,43)$, was considered as the average BSA of the 25-year-old American adult. Since, $1.73 \mathrm{~m}^{2}$ has become a classic BSA standardized parameter and has been used for physiological parameters such as GFR, and cardiac output. Ogden et al. reported (44) that American adults gained weight faster than they gained height from 1960 to 2002, and by 2002, the BSA of 25-year-old healthy adults in the United States had increased from $1.73 \mathrm{~m}^{2}$ in 1927 to $1.92 \mathrm{~m}^{2}$. Several studies have also shown that the mean differences between absolute and BSA normalized GFR are larger in patients with extreme body sizes (45). Heaf reported that BSA is not the best indexing parameter and is possibly even inaccurate, with the current standard BSA of $1.73 \mathrm{~m}^{2}$ bearing little resemblance to the BSA of modern Western populations (46). The selection of $1.73 \mathrm{~m}^{2}$ might be one possible reason for the dependence of normalized GFR on body height. Additionally, the choice of different standardization formulas is also one of the possible reasons influencing the conclusions of this study. There are different formulas for calculating BSA, among which the most commonly used formula is the Du Bois and Du Bois equation, which was 
based on only 8 adults and a 21 -month-old infant weighing $6.27 \mathrm{~kg}$ in $1916(47,48)$. Some studies have stated that the Du Bois and Du Bois equation underestimates BSA $(48,49)$. Meanwhile, the BSA formula of Yu et al. obtained from 3,951 Chinese individuals using three-dimensional whole body scanning technology is considered to be more accurate than the traditional direct measurement and indirect estimation methods (48); it has been verified in Chinese adults and is regarded as the definitive method for measuring BSA (46). It is therefore necessary to compare the differences in BSA and GFR between the formula proposed by $\mathrm{Yu}$ et al. and the traditional formula of DuBois and DuBois in Chinese adults in future studies.

\section{Conclusions}

In conclusion, the normal reference ranges for renal depth-calibrated gSGFR (L), gSGFR (R), and gTGFR for healthy Chinese adults aged between 23-64 years old, 41-50 years old, and 51-60 years old have been established preliminarily, and could potentially be used as an initial guide in determining healthy renal function in China. The study also determined that gSGFR (L), gSGFR (R), and gTGFR decreased with age and body height, but had no relationship with gender, body weight, or BMI. Further study with a larger number of patients is warranted.

\section{Acknowledgments}

Funding: None.

\section{Footnote}

Conflicts of Interest: All authors have completed the ICMJE uniform disclosure form (available at http://dx.doi. org/10.21037/qims-19-772). The authors have no conflicts of interest to declare.

Ethical Statement: This study was reviewed and approved by the Ethics Committee of the First Affiliated Hospital of Xi'an Jiaotong University (Xi'an, China), and all patients signed a written informed consent before participating in the study.

Open Access Statement: This is an Open Access article distributed in accordance with the Creative Commons Attribution-NonCommercial-NoDerivs 4.0 International License (CC BY-NC-ND 4.0), which permits the non- commercial replication and distribution of the article with the strict proviso that no changes or edits are made and the original work is properly cited (including links to both the formal publication through the relevant DOI and the license). See: https://creativecommons.org/licenses/by-nc-nd/4.0/.

\section{References}

1 Berg UB. Differences in decline in GFR with age between males and females. Reference data on clearances of inulin and PAH in potential kidney donors. Nephrol Dial Transplant 2006;21:2577-82.

2 Thomas L, Huber AR. Renal function-estimation of glomerular filtration rate. Clin Chem Lab Med 2006;44:1295-302.

3 Stevens LA, Coresh J, Greene T, Levey AS. Assessing kidney function-measured and estimated glomerular filtration rate. N Engl J Med 2006;354:2473-83.

4 Motie M, Evangelista LS, Lombardo D, Hoi J, Horwich TB, Hamilton M, Fonarow GC. Effect of weight loss on renal function in overweight and obese patients with heart failure. Diabetes Metab Syndr 2017;11:95-8.

5 Sawyer WT, Canaday BR, Poe TE, Webb CE, Porter RS, Gal P, Joyner PU, Berry J, Shearer SW, Paoloni CU. A multicenter evaluation of variables affecting the predictability of creatinine clearance. Am J Clin Pathol 1982;78:832-8.

6 Blaufox MD, Aurell M, Bubeck B, Fommei E, Piepsz A, Russell C, Taylor A, Thomsen HS, Volterrani D. Report of the Radionuclides in Nephrourology Committee on Renal Clearance. J Nucl Med 1996;37:1883-90.

7 Price M. Comparison of crealinine clearance to inulin clearance in the determination of glomerular filtration rate. J Urol 1972;107:339-40.

8 Godfrey T, Cuadrado MJ, Fofi C, Abbs I, Khamashta MA, Nunan T, Hughes GR. Chromium-51 ethylenediamine tetraacetic acid glomerular filtration rate: a better predictor than glomerular filtration rate calculated by the Cockcroft-Gault formula for renal involvement in systemic lupus erythematosus patients. Rheumatology (Oxford) 2001;40:324-8.

9 Russell CD. Optimum sample times for single-injection, multisample renal clearance methods. J Nucl Med 1993;34:1761-5.

10 Itoh K. Comparison of methods for determination of glomerular filtration rate: Tc-99m-DTPA renography, predicted creatinine clearance method and plasma sample method. Ann Nucl Med 2003;17:561-5. 
11 Ma G, Shao M, Xu B, Tian J, Chen Y. Glomerular filtration rate measured by $99 \mathrm{~m}$ Tc-DTPA Gates method is not significantly affected by the premature or delayed initiation of image acquisition. Quant Imaging Med Surg 2019;9:1103-9.

12 Gutte H, Møller ML, Pfeifer AK, Thorup J, Borgwardt L, Borgwardt L, Kristoffersen US, Kjaer A. Estimating GFR in children with 99m Tc-DTPA renography: a comparison with single-sample 51Cr-EDTA clearance. Clin Physiol Funct Imaging 2010;30:169-74.

13 Garcia-Covarrubias L, Barragan J, Castro I, Hernandez K, Reding A, Hinojosa H, Prieto P, Garcia A, Alejandra C, Ortuño D, Carmona M, Fernández D, Diliz H. Correlation of the Glomerular Filtration Rate Measured With the Use of DTPA-Tc99m in Live Kidney Donors With Equations Based on Creatinine and Cystatin C. Transplant Proc 2018;50:423-7.

14 Gates GF. Glomerular filtration rate: estimation from fractional renal accumulation of 99m Tc-DTPA (stannous). AJR Am J Roentgenol 1982;138:565-70.

15 Gates GF. Split renal function testing using Tc-99m DTPA. A rapid technique for determining differential glomerular filtration. Clin Nucl Med 1983;8:400-7.

16 Itoh K, Tsushima S, Tsukamoto E, Tamaki N. Reappraisal of single-sample and gamma camera methods for determination of the glomerular filtration rate with 99mTc-DTPA. Ann Nucl Med 2000;14:143-50.

17 Levey AS, Coresh J, Greene T, Marsh J, Stevens LA, Kusek JW, Van Lente F, Chronic Kidney Disease Epidemiology Collaboration. Expressing the Modification of Diet in Renal Disease Study equation for estimating glomerular filtration rate with standardized serum creatinine values. Clin Chem 2007;53:766-72.

18 Taylor A, Lewis C, Giacometti A, Hall EC, Barefield KP. Improved formulas for the estimation of renal depth in adults. J Nucl Med 1993;34:1766-9.

19 Xue J, Deng H, Jia X, Wang Y, Lu X, Ding X, Li Q, Yang A. Establishing a new formula for estimating renal depth in a Chinese adult population. Medicine 2017;96:e5940.

20 Inoue Y, Yoshikawa K, Suzuki T, Katayama N, Yokoyama I, Kohsaka T, Tsukune Y, Ohtomo K. Attenuation correction in evaluating renal function in children and adults by a camera-based method. J Nucl Med 2000;41:823-9.

21 Steinmetz AP, Zwas ST, Macadziob S, Rotemberg G, Shrem Y. Renal depth estimates to impmve the accuracy of glomemlar fihration rate. J Nucl Med 1998;39:1822-5.

22 Liu Y, Zhao AM, Yang LL, Wand Q, Zhang YM, Yang AM, Tian PX, Xue JJ. Renal depth measured by CT optimize the glomerular filtration rate using the Gates method in living donor kidney transplantation. Chinese Journal of Organ Transplantation 2019;40:195-9.

23 Branch of Organ Transplantation of Chinese Medical Association, Branch of Organ Transplant Physician of Chinese Medical Doctor Association. Clinical guideline on living donor renal transplantation in China (2016 Edition). Organ Transplantation 2016;6:417-26.

24 Granerus G, Moonen M. Effects of extra-renal background subtraction and kidney depth correction in the measurement of GFR by gamma camera renography. Nucl Med Commun 1991;12:519-27.

25 Maneval DC, Magill HL, Cypess AM, Rodman JH. Measurement of skin-to-kidney distance in children: implications for quantitative renography. J Nucl Med 1990;31:287-91.

26 Pottel H, Delanaye P, Weekers L, Selistre L, Goffin K, Gheysens O, Dubourg L. Age-dependent reference intervals for estimated and measured glomerular filtration rate. Clin Kidney J 2017;10:545-51.

27 Yang Q, Wang C, Gao C, Maimaiti W, Li S, Jiang L, Shen $\mathrm{M}$, Shen Y. Does baseline renal function always decrease after unilateral ureteral severe obstruction? - experimental validation and novel findings by Tc-99m-diethylene triamine pentaacetate acid (DTPA) dynamic renal scintigraphy. Quant Imaging Med Surg 2019;9:1451-65.

28 Uchiyama K, Kuniyasu Y, Niio Y, Hasebe S, Yamada M, Shinohara H, Matsuoka S, Shima H, Obuchi M, Takizawa K, Honda M, Kawabe R, Kuwayama J, Iwasaki $\mathrm{S}$, Ideura T. Proposal on new formulas for renal depth in the technetium-99m-mercaptoacetyltriglycine (MAG3) scintigraphy. Kaku Igaku 1997;34:159-66.

29 Ma G, Shao M, Xu B, Tian J, Chen Y. Establish New Formulas for the Calculation of Renal Depth in Both Children and Adults. Clin Nucl Med 2015;40:e357-62.

30 Sugawara S, Ishii S, Kojima Y, Ito H, Suzuki Y, Oriuchi N. Feasibility of gamma camera-based GFR measurement using renal depth evaluated by lateral scan of $99 \mathrm{mTc}-$ DTPA renography. Ann Nucl Med 2020;34:349-57.

31 Awdeh M, Kouris K, Hassan IM, Abdel-Dayem HM. Factors affecting the Gates' measurement of glomerular filtration rate. Am J Physiol Imaging 1990;5:36-41.

32 Gruenewald SM, Collins LT, Fawdry RM. Kidney Depth Measurement and Its Influence on Quantitation of Function from Gamma Camera Renography. Clin Nucl Med 1985;10:398-401.

33 Grewal GS, Blake GM. Reference data for $51 \mathrm{Cr}$ EDTA measurements of the glomerular filtration rate 
derived from live kidney donors. Nucl Med Commun 2005;26:61-5.

34 Granerus G, Aurell M. Reference values for 51Cr-EDTA clearance as a measure of glomerular filtration rate. Scand J Clin Lab Invest 1981;41:611-6.

35 Piepsz A, Tondeur M, Ham H. Revisiting normal 51Crethylenediaminetetraacetic acid clearance values in children. Eur J Nucl Med Mol Imaging 2006;33:1477-82.

36 Piepsz A, Tondeur M, Ham H. Escaping the correction for body surface area when calculating glomerular filtration rate in children. Eur J Nucl Med Mol Imaging 2008;35:1669-72.

37 Fenton A, Montgomery E, Nightingale P, Peters AM, Sheerin N, Wroe AC. Glomerular filtration rate: new ageand gender-specific reference ranges and thresholds for living kidney donation. BMC Nephrol 2018;19:336.

38 Wesson L. Renal hemodynamics in physiological states. In: Wesson L, editor. Physiology of the human kidney. New York: Grune \& Stratton, 1969:96-108.

39 Baylis C, Corman B. The aging kidney: insights from experimental studies. J Am Soc Nephrol 1998;9:699-709.

40 Pottel H, Hoste L, Yayo E, Delanaye P. Glomerular Filtration Rate in Healthy Living Potential Kidney Donors: A Meta-Analysis Supporting the Construction of the Full Age Spectrum Equation. Nephron 2017;135:105-19.

41 Redal-Baigorri B, Rasmussen K, Heaf JG. Indexing glomerular filtration rate to body surface area: clinical

Cite this article as: Wei Y, Liu Y, Li Q, Zhang Y, Wang Q, Yang Y, Liang Y, Zhao A, Yang A, Xue J. Establishment of normal reference ranges for total and separate glomerular filtration rates in living kidney donors by Gates' method after renal depth measured using single-photon emission computed tomography/computed tomography. Quant Imaging Med Surg 2020;10(12):2297-2306. doi: 10.21037/qims-19-772 consequences. J Clin Lab Anal 2014;28:83-90.

42 McIntosh JF, Möller E, Van Slyke DD. Studies of urea exretion. III: The influence of body size on urea output. J Clin Invest 1928;6:467-83.

43 Heaf JG. The origin of the 1.73-m2 body surface area normalization:problems and implications. Clin Physiol Funct Imaging 2007;27:135-7.

44 Ogden CL, Fryar CD, Carroll MD, Flegal KM. Mean body weight, height, and body mass index, United States 1960-2002. Adv Data 2004;27:1-17.

45 Delanaye P, Radermecker RP, Rorive M, Depas G, Krzesinski JM. Indexing glomerular filtration rate for body surface area in obese patients is misleading:Concept and example. Nephrol Dial Transplant 2005;20:2024-8.

46 Heaf J. The Uses and Misuses of Body Surface Area in Medicine. In: Preedy V. editor. Handbook of Anthropometry. NY: Springer, 2012:307-20.

47 Verbraecken J, Van de Heyning P, De Backer W, Van Gaal L. Body surface area in normal-weight, overweight, and obese adults. A comparison study. Metabolism 2006;5 5:515-24.

48 Yu CY, Lo YH, Chiou WK. The 3D scanner for measuring body surface area: a simplified calculation in the Chinese adult. Appl Ergon 2003;34:273-8.

49 Sendroy J, Collison HA. Nomogram for determination of human body surface area from height and weight. J Appl Physiol 1954;7:1-12. 
Supplementary

Gates' method

$\operatorname{GFR}(\mathrm{mL} / \mathrm{min})=9.81272 \% \mathrm{RU}-6.82519$;

$$
\% \mathrm{RU}=\frac{\mathrm{Cr} / \mathrm{e}^{-0.153 \mathrm{R}}+\mathrm{Cl} / \mathrm{e}^{-0.153 \mathrm{~L}}}{\text { Cpre }- \text { Cpost }}
$$

\section{Itoh and arakawa method}

$\operatorname{Ccr}(\mathrm{mL} / \mathrm{min})=13.15 \% \mathrm{RU}^{0.787}$

$$
\% \mathrm{RU}=\frac{\mathrm{Cr} / \mathrm{e}^{-0.153 \mathrm{R}}+\mathrm{Cl} / \mathrm{e}^{-0.153 \mathrm{~L}}}{\text { Cpre }- \text { Cpost }}
$$

In both

$\% \mathrm{RU}=\%$ uptake / total injected dose at 2-3 min post injection

$\mathrm{Cr}=$ counts in the right kidney for 1 minute at $2-3$ min post injection

$\mathrm{Cl}=$ counts in the left kidney for 1 minute at $2-3 \mathrm{~min}$ post injection

Cpre $=$ pre-injection counts $/ \mathrm{min}$

Cpost $=$ post-injection counts $/ \mathrm{min}$

In Gates' method (renal depth was estimated by Tønnesen formula)

$\mathrm{R}=$ right renal depth $(\mathrm{cm})=13.3 \times \mathrm{W} / \mathrm{H}+0.7$

$\mathrm{L}=$ left renal depth $(\mathrm{cm})=13.2 \times \mathrm{W} / \mathrm{H}+0.7$

$\mathrm{W} / \mathrm{H}=$ body weight $(\mathrm{kg}) /$ height $(\mathrm{cm})$

In Itoh and Arakawa' method (The renal depth was estimated by Itoh formula)

$\mathrm{R}=$ right renal depth $(\mathrm{cm})=13.636 \times \mathrm{W} / \mathrm{H}^{0.996}$

$\mathrm{L}=$ left renal depth $(\mathrm{cm})=14.0285 \times \mathrm{W} / \mathrm{H}^{0.7554}$

$\mathrm{W} / \mathrm{H}=$ body weight $(\mathrm{kg}) /$ height $(\mathrm{cm})$ 